\title{
Friction and Wear Properties of CrAl-Based Coatings for Nuclear Fuel Cladding
}

\author{
Biao Ma, Bin Luo, Zhuozheng Wang, Chuiyi Meng and Xiujie He* \\ Sino-French Institute of Nuclear Engineering and Technology, Sun Yat-sen University, Zhuhai, China
}

\section{OPEN ACCESS}

Edited by:

Shanfang Huang,

Tsinghua University, China

Reviewed by:

Jinliang Song,

Chinese Academy of Sciences, China

Rong Liu,

South China University of Technology,

China

*Correspondence:

Xiujie $\mathrm{He}$

hexiujie@mail.sysu.edu.cn

Specialty section:

This article was submitted to

Nuclear Energy,

a section of the journal

Frontiers in Energy Research

Received: 29 October 2020

Accepted: 18 January 2021

Published: 23 February 2021

Citation:

Ma B, Luo B, Wang Z, Meng $C$ and He $X$ (2021) Friction and Wear Properties of CrAl-Based Coatings for Nuclear Fuel Cladding.

Front. Energy Res. 9:622708. doi: 10.3389/fenrg.2021.622708
Friction and wear performance is one of the key mechanical properties of accident tolerant fuel cladding coatings. In this study, reciprocating sliding wear tests had performed on two types of CrAl and CrAIN coatings with two different $\mathrm{Al}$ content ratios and $\mathrm{Zr}-4$. The coefficient of friction, wear depth, and abrasion loss were measured and compared. The results indicated that the CrAl-based coatings improve the wear behavior significantly and nitrogen has an obvious improvement on the wear resistance of the coating. The friction and wear performance was also studied in a water environment. The results show that the presence of water degrade the wear performance of $\mathrm{Zr}-4$ and CrAl coatings but ameliorates the friction and wear performance of CrAIN coatings. The feasibility of depositing ATF coating on conventional $\mathrm{Zr}$-4 substrates to mitigate the influence of grid-to-rod fretting was demonstrated.

Keywords: accident-tolerant fuel, coating, chromium-aluminum coatings, friction and wear behavior, reciprocating wear

\section{INTRODUCTION}

$\mathrm{Zr}$ alloys are widely used in the nuclear area because of its low neutron absorbing cross-section, good mechanical properties, and high corrosion resistance in reactor water (Choudhuri et al., 2012; Cekić et al., 2013; Kuprin et al., 2015). However, in the Fukushima nuclear accident, under the loss of coolant accident condition, zirconium reacts violently with water to produce a large amount of hydrogen, which causes the explosion and the radiation leak (Buesseler et al., 2011; Blandford and Ahn, 2012; Buesseler et al., 2012). These risks show that it is essential to improve the fuel safety and continually study the fuel degradation phenomena (Kurata et al., 2018). Hence, the researchers propose a new fuel system named accident-tolerant fuel (ATF). The ATF can be defined as a new system that increases the accident tolerance of loss of coolant accident condition over a long period of time while maintaining or improving fuel performance during normal operation condition (Zinkle et al., 2014; Kim et al., 2016; Terrani, 2018). One of the currently recognized method of the investigation of ATF is to deposit a coating on the $\mathrm{Zr}-4$ cladding. A number of studies have exposed that ceramic coatings have excellent resistance to oxidation at high temperature, such as silicon carbide coating (Katoh et al., 2014; Deck et al., 2015; Stone et al., 2015), TiAlCrN (Ma et al., 2019), and $\mathrm{CrN}$ (Meng et al., 2019), thus avoiding the oxidation of $\mathrm{Zr}-4$ at high temperature. The other is to use the metallic coatings. For example, FeCrAl coatings, as Fe-based alloys have a high oxidation resistance (Zinkle et al., 2014; Pint et al., 2015; Massey et al., 2016). Cr coating is also used, because it has excellent corrosion resistance under severe condition on Zircoloy (Park et al., 2015; Brachet et al., 2016; Tang et al., 2017; He et al., 2019). Nowadays, CrAl-based coatings have attracted remarkable attention due to their excellent oxidation resistance. Zhong et al. (Zhong et al., 2018) performed hightemperature steam exposure to assess the oxidation behavior of $\mathrm{CrAl}$ coatings. It was demonstrated 
that $\mathrm{CrAl}$ coatings with higher $\mathrm{Al}$ composition has lower weight gain in high temperature steam. Chen et al. (Chen et al., 2016) introduced $\mathrm{TiN}$ and $\mathrm{ZrN}$ insertion layer into CrAlN coating to study its mechanical and thermal properties. The results exhibit that CrAlN/TiN coating have a higher hardness than CrAlN/ZrN coating and TiN insertion layer have an improvement on the thermal stability of CrAlN coatings. Li et al. (Li et al., 2014) deposited CrAlN coatings with $\mathrm{Zr}$ alloying ( $\mathrm{Zr}$ contents from 0 to 29.5 at.\%) by d.c. reactive magnetron sputtering and investigated their mechanical properties, thermal stability, and oxidation resistance. They suggested that the coating hardness is improved by alloying of low contents of Zr. Zhang et al. (Zhang et al., 2019) used high current pulsed electron beam to deposit a $\mathrm{CrAl}$ coating on $\mathrm{Al}$ to study its microstructure and properties. They found that the microhardness and corrosion resistance were ameliorated because of the presence of $\mathrm{Cr}$ element.

Most published work mainly focused on the oxidation behavior and corrosion behavior of CrAl-based coatings nowadays. However, there are few studies on the friction and wear behavior of this coating. Furthermore, the influence of the water environment on the friction and wear behavior of this coating has not been investigated in details. In fact, in addition to oxidation performance, the mechanical properties of ATF also play an important role. In nuclear reactor components, such as fuel assemblies, flow induced vibrations can cause severe fretting wear (Rubiolo, 2006; Rubiolo and Young, 2009). Fretting is a low amplitude oscillatory motion between contacting bodies which leads to wear and fatigue damage (Neu, 2011). Many parameters such as amplitude, normal force, and coefficient of friction affect the type of wear and fatigue damage (Waterhouse, 1992). The grid-to-rod fretting (GTRF) is the most common cause of the fuel failure, and fuel rod fretting is a significant issue for designers of pressurized water reactor fuels (Edsinger et al., 2009). It is generally acknowledged that the turbulence from flow induced vibrations will cause the GTRF at the contact point between the grid and the fuel rod (Kim et al., 2016). According to the past research, the mechanism of GTRF degradation depends extremely on the grid-to-rod gap as a function of burnup, in particular under condition of high flow rates which is the vibration caused by the excessive flow (Kim and Lee, 2003; Kovács et al., 2009, Kovács et al., 2013; Jiang et al., 2016). Though the reliability of nuclear fuels can be increased by the new design features to strengthen the wear resistance of spacer grids with the same $\mathrm{Zr}$ alloy, the irradiation causes the fuel rod to elongate in the axial direction, and the thermal creep caused by the pressure difference between the inside and outside of the cladding results in radial contraction. These two factors lead to a gradual increasement of the grid-to-rod gap. It is excessively difficult to avoid this phenomenon under condition of operating temperature and high neutron irradiation. As a result, the wear behavior becomes the important parameters of the ATF and the tribological properties of new ATF material is not clearly understood. Therefore, it is worthy to study on the friction and wear behavior of new ATF materials.

In this work, CrAl-based coatings were deposited on $\mathrm{Zr}-4$ by multi-arc ion plating. The GTRF situation is characterized by the
TABLE 1 | Concentration of $\mathrm{Cr}, \mathrm{Al}$, and $\mathrm{N}$ in the CrAl-based coatings and echanical properties for ATF candidates and $\mathrm{Zr}-4$.

\begin{tabular}{lccccc} 
Material & $\begin{array}{c}\text { Target Cr:Al ratio (at. } \\
\text { \%) }\end{array}$ & \multicolumn{3}{c}{$\begin{array}{c}\text { Element } \\
\text { proportions (at.\%) }\end{array}$} & Hardness [HV] \\
\cline { 3 - 5 } & & Cr & Al & N & \\
\hline Zr-4 & - & - & - & - & 234 \\
CrAl-1 & $30: 70$ & 32.1 & 67.9 & - & 380 \\
CrAl-2 & $50: 50$ & 45.8 & 54.2 & - & 390 \\
CrAlN-1 & $30: 70$ & 17.4 & 36.7 & 46.0 & 1,020 \\
CrAlN-2 & $50: 50$ & 35.1 & 25.6 & 39.4 & 1,080 \\
\hline
\end{tabular}

friction and wear of the coating with a zirconia ball under different conditions, i.e., unlubricated condition and water lubrication condition. The results show that CrAlN coatings' friction and wear performance is more predominant than that of $\mathrm{CrAl}$ coatings, and the CrAlN coating with lower $\mathrm{Al}$ composition have the best friction and wear performance.

\section{EXPERIMENT PROCEDURE}

In this study, four ATF candidates (two CrAl coatings and two CrAlN coatings with different $\mathrm{Al}$ content the detail is exhibited in Table 1) and a conventional Zr-4 alloy with a length of $25 \mathrm{~mm}$, a width of $15 \mathrm{~mm}$ and a thickness of $2 \mathrm{~mm}$ were prepared and tested. The coatings are deposited on the $\mathrm{Zr}-4$ alloy substrate by multi-arc ion plating. The deposition time of $\mathrm{CrAl}$ coatings is $2 \mathrm{~h}$ and $6 \mathrm{~h}$, and for CrAlN coatings, the deposition time is $2 \mathrm{~h}$. The hardness of $\mathrm{Zr}-4$ and four CrAl-based coatings were measured by Vickers hardness tester and the results are shown in Table 1. The friction and wear tests were in progress in a reciprocating sliding tester at room temperature $\left(27^{\circ} \mathrm{C}\right)$ in unlubricated (air) condition and in water lubrication. For the water lubrication condition, the specimens were placed in a tank filled with deionized water. The effects of water fluidity, temperature, and hydrochemistry on the results were not taken into account. The schematic diagram of test machine is shown in Figure 1. Each specimen is subjected to a friction test with a zirconia ball. The reciprocating stroke is fixed at $10 \mathrm{~mm}$, the reciprocating frequency is $13 \mathrm{~Hz}$, and the friction time is $3 \mathrm{~min}$ and $10 \mathrm{~min}$. Since the friction and wear properties of coatings cannot be clearly compared with either too large or too small loads, the contact normal forces of 1 and $5 \mathrm{~N}$ are applied under the experiment condition. During the experiment, the coefficient of friction (COF) was continuously monitored in order to observe the relationship between the change of COF curve and the wear amount of each sample. After the wear test, the worn surface of each sample is observed by the surface profilometer to measure the wear depth and the amount of friction wear. The amount of wear volume was detected using a non-contact three-dimensional laser interferometer.

To characterize the coatings, X-ray diffraction (XRD) was conducted to determine the phase composition of samples. The energy-dispersive X-ray spectroscopy (EDS) profiles were performed to study the distribution of $\mathrm{Cr}, \mathrm{Al}$, and $\mathrm{N}$ elements. The scanning electron microscopy (SEM) was applied to assess 


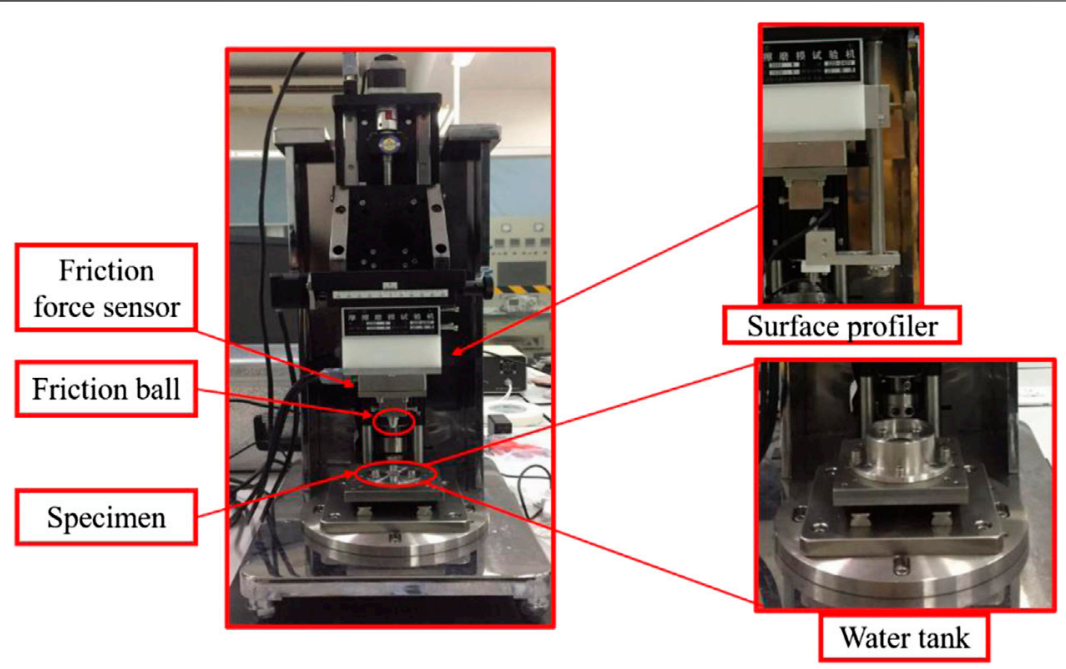

FIGURE 1 | CFT-I type friction wear testing machine.
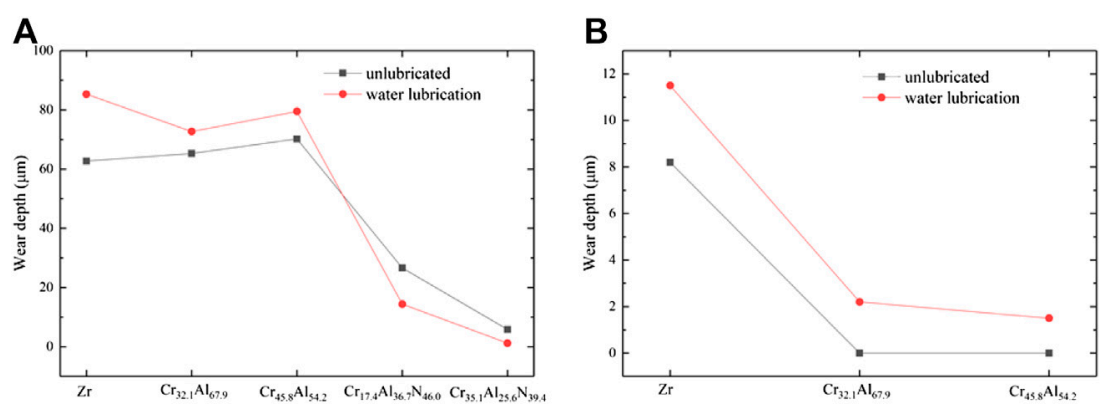

FIGURE 2 | Wear depth for various ATF candidates as a function of load and time under unlubricated and water lubrication condition: (A) 5 N, 10 min; (B) 1 N, $3 \mathrm{~min}$.

the coatings thickness and adhesion with substrate. Meanwhile, nanoindentation test was performed to assess the mechanical properties of coatings.

\section{RESULTS AND DISCUSSION}

\section{Wear Behavior}

After the reciprocating sliding friction test, the wear depth was obtained from the bottom sample. Figure 2 depicts the measurements of the maximum wear depth for various ATF coating under different loads in unlubricated and water lubrication condition, the experiment time is 10 and $3 \mathrm{~min}$. The difference in wear depth of different samples is considered as the difference in the friction and wear performance of the samples. It can be found that the wear depth under different loads is quite different, which indicates that different loads have different effects on the damage of the coating. Under a load of $5 \mathrm{~N}$, it will be found that $\mathrm{Zr}, \mathrm{Cr}_{32.1} \mathrm{Al}_{67.9}$, and $\mathrm{Cr}_{45.8} \mathrm{Al}_{54.2}$ have similar wear depths. Under a load of $1 \mathrm{~N}$, the wear depth of the $\mathrm{CrAl}$ coating will be smaller than that of $\mathrm{Zr}$.
This shows that when the load is small, the CrAl coating has a protective effect on the $\mathrm{Zr}$ substrate. However, the coating was destructed by relatively large load, which will lead to the disappearance of the protective effect of the CrAl coating on the $\mathrm{Zr}$ substrate. Furthermore, it can be found that under the load of $5 \mathrm{~N}$, the CrAlN coatings have a more significant protective effect on the $\mathrm{Zr}$ substrate compared to the $\mathrm{CrAl}$ coatings. At the same time, the wear performance of the $\mathrm{Cr}_{35.1} \mathrm{Al}_{25.6} \mathrm{~N}_{39.4}$ coating is better than that of the $\mathrm{Cr}_{17.4} \mathrm{Al}_{36.7} \mathrm{~N}_{46.0}$ coating due to the smaller wear depth.

The presence of water also has influence on wear performance, in addition, the impact on $\mathrm{CrAl}$ coatings and CrAlN coatings is distinct. For $\mathrm{Zr}, \mathrm{Cr}_{32.1} \mathrm{Al}_{67.9}$, and $\mathrm{Cr}_{45.8} \mathrm{Al}_{54.2}$ coatings, under 1 and $5 \mathrm{~N}$ loads, the wear depths under water lubrication are more significant than that under unlubricated condition. For $\mathrm{Cr}_{17.4} \mathrm{Al}_{36.7} \mathrm{~N}_{46.0}$ and $\mathrm{Cr}_{35.1} \mathrm{Al}_{25.6} \mathrm{~N}_{39.4}$, the wear depths under water lubrication are less than that under unlubricated condition. It is considered that the wear behavior of $\mathrm{CrAl}$ coatings and CrAlN coatings in water environment is different (He et al., 2020). For the $\mathrm{CrAl}$ coatings and $\mathrm{Zr}-4$, the wear behavior is abrasive wear, during this process, there will be 


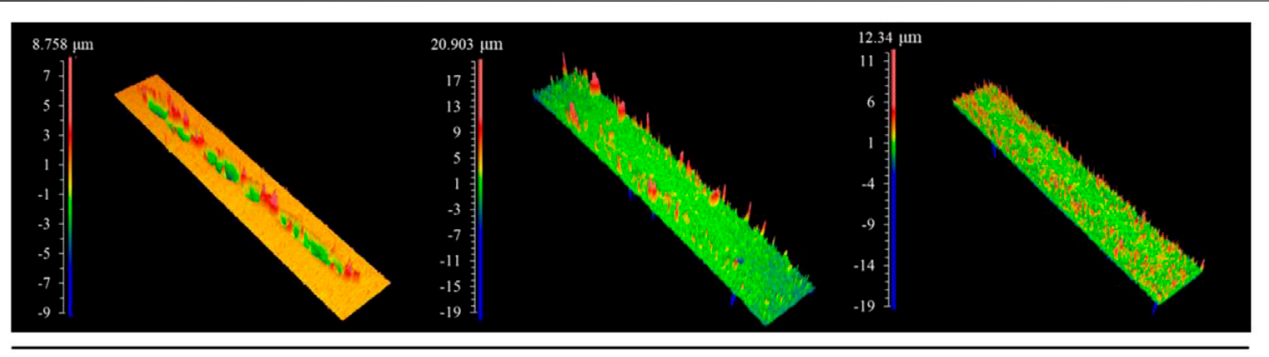

\begin{tabular}{lccc}
\hline $1 \mathrm{~N}$ water lubrication & $\mathrm{Zr}$ & $\mathrm{Cr}_{32,1} \mathrm{Al}_{679}$ & $\mathrm{Cr}_{458} \mathrm{Al}_{542}$ \\
\hline Wear volume $\left(\mu \mathrm{m}^{3}\right)$ & $2.65 \times 10^{6}$ & exceed limit & exceed lmit \\
\hline
\end{tabular}

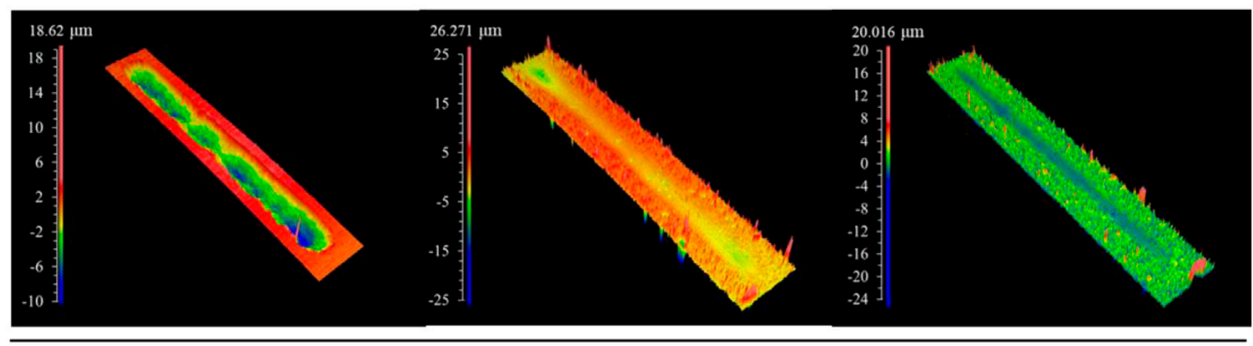

\begin{tabular}{lccc}
\hline $1 \mathrm{~N}$ water lubrication & $\mathrm{Zr}$ & $\mathrm{Cr}_{32,1} \mathrm{Al}_{679}$ & $\mathrm{Cr}_{458} \mathrm{Al}_{542}$ \\
\hline Wear volume $\left(\mu \mathrm{m}^{3}\right)$ & $1.21 \times 10^{7}$ & $2.82 \times 10^{6}$ & $4.78 \times 10^{5}$ \\
\hline
\end{tabular}

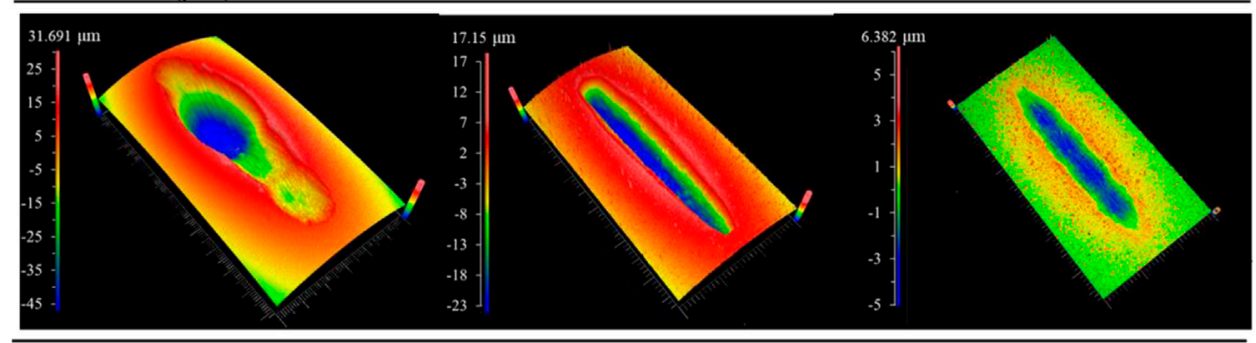

\begin{tabular}{lccc}
\hline $5 \mathrm{~N}$ unlubricated & $\mathrm{Zr}$ & $\mathrm{Cr}_{174} \mathrm{Al}_{367} \mathrm{~N}_{460}$ & $\mathrm{Cr}_{351} \mathrm{Al}_{256} \mathrm{~N}_{394}$ \\
\hline Wear volume $\left(\mu \mathrm{m}^{3}\right)$ & $1.67 \times 10^{8}$ & $6.2 \times 10^{7}$ & $6.45 \times 10^{6}$ \\
\hline
\end{tabular}

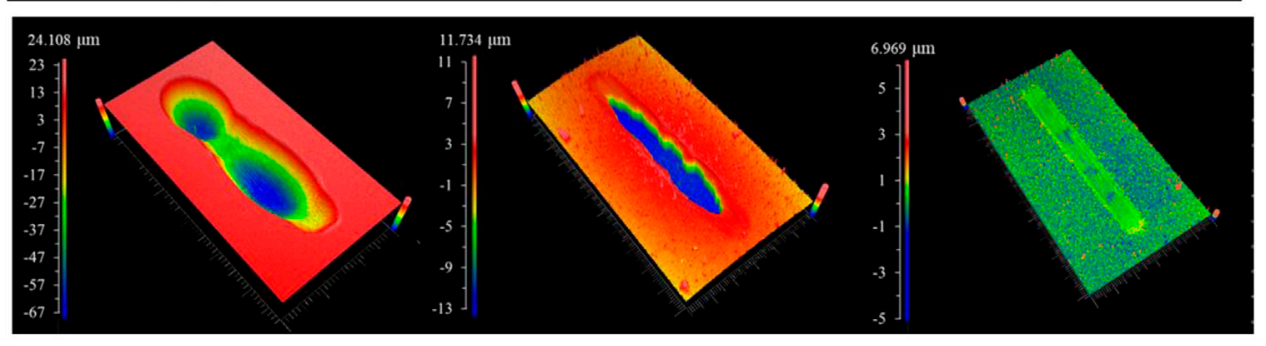

\begin{tabular}{lccc}
\hline $5 \mathrm{~N}$ unlubricated & $\mathrm{Zr}$ & $\mathrm{Cr}_{174} \mathrm{Al}_{367} \mathrm{~N}_{460}$ & $\mathrm{Cr}_{351} \mathrm{Al}_{256} \mathrm{~N}_{394}$ \\
\hline Wear volume $\left(\mu \mathrm{m}^{3}\right)$ & $2.28 \times 10^{8}$ & $2.34 \times 10^{7}$ & $1.78 \times 10^{5}$ \\
\hline
\end{tabular}

FIGURE 3 | Results of noncontact three-dimensional optical profilometry under different conditions.

debris attached to the scratched surface, which lead to the increasement of wear depth. For the CrAlN coatings, the wear behavior is adhesive wear, the lubrication during friction reduce the degree of wear.

In order to assess the lubricant effect to the wear of various coatings more accurately, for the $\mathrm{CrAl}$ coatings, a 3-minute friction and wear under water lubrication and unlubricated condition was carried out under a load of $1 \mathrm{~N}$. Zr-4 was also tested as a control group under the same condition. For the
CrAlN coatings, a 10-minute friction and wear test under water lubrication and unlubricated condition was conducted, identically, Zr-4 had the experiment under the same condition. After the experiment, the scratches were measured using noncontact three-dimensional optical profilometry.

According to Figure 3, the wear shapes of various ATF candidate coatings and $\mathrm{Zr}-4$ are substantially similar under the presence or absence of lubrication condition. The wear shape of the $\mathrm{Zr}-4$ and the $\mathrm{CrAl}$ coatings is largely different from the wear 

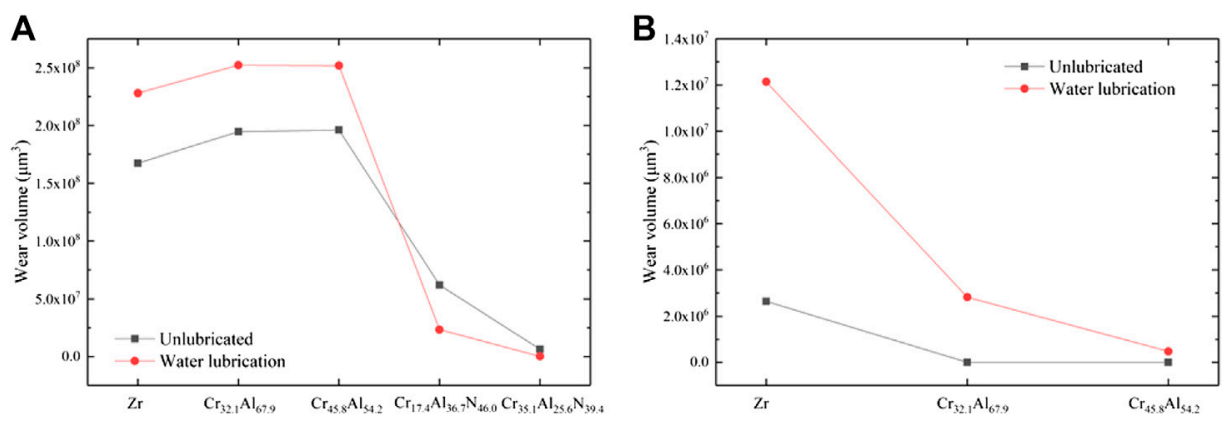

FIGURE 4 | Abrasion loss for Zr-4 and various ATF coatings under different loads: (A) $5 \mathrm{~N}$, (B) $1 \mathrm{~N}$.

shape of the CrAlN coatings, which can be rationalized by the degree of damage of the coatings. As can be seen from the results of the noncontact three-dimensional optical profilometry, the surface of the coating is relatively rough. The shallower the scratch, the rougher the surface is observed. For the $\mathrm{Cr}_{32.1} \mathrm{Al}_{67.9}$ and $\mathrm{Cr}_{45.8} \mathrm{Al}_{54.2}$ coatings under unlubricated condition, the wear depth is too small, which has exceeded the lower limit of the noncontact three-dimensional optical profilometry measurement. Compared with unlubricated condition, the uncoated $\mathrm{Zr}-4, \mathrm{Cr}_{32.1} \mathrm{Al}_{67.9}$, and $\mathrm{Cr}_{45.8} \mathrm{Al}_{54.2}$ coatings wear more under water lubrication condition. Meanwhile the wear depth of CrAlN coatings under water lubrication condition are less than that of unlubricated condition, which is consistent with the results obtained by the scratch measurement instrument. Under the same condition, it can be realized that the $\mathrm{Zr}-4$ with coatings have less wear debris than uncoated $\mathrm{Zr}-4$. Thus, the CrAl-based coatings has a protective effect on the substrate and enhances the wear resistance.

As can be seen from the results of the noncontact threedimensional optical profilometry, the surface of the coating is relatively rough. When the wear depth is smaller, the surface roughness observed in the noncontact three-dimensional optical profilometry is more obvious, because the sample surface has an unevenness of about $0.5 \mu \mathrm{m}$, which is not negligible in the noncontact three-dimensional optical profilometry result when the wear depth is small. Whereas the wear depth under $5 \mathrm{~N}$ is deep, and the unevenness of the surface is negligible, thus this difference is produced in the picture results of the noncontact three-dimensional optical profilometry.

The abrasion loss of $\mathrm{Zr}-4$ and two $\mathrm{CrAl}$ coatings increased under the condition of water lubrication. According to the results of the noncontact three-dimensional optical profilometry, water lubrication has influence on the scratch shape, hence, the main reason for this result was the change of wear depth. This is consistent with previous results. Figure 4 reveals the wear volume of each ATF coatings after experiment with different conditions. The abrasion loss of CrAlN coating has little change, among which the abrasion loss of $\mathrm{Cr}_{35.1} \mathrm{Al}_{25.6} \mathrm{~N}_{39.4}$ has almost no change, which indicates that it has good wear resistance under both conditions.

Under a load of $1 \mathrm{~N}$, the abrasion loss of the $\mathrm{CrAl}$ coating is much less than that of $\mathrm{Zr}$ under unlubricated and water lubrication conditions, and shows a good protective effect on the $\mathrm{Zr}$ substrate, which is consistent with the previous results.
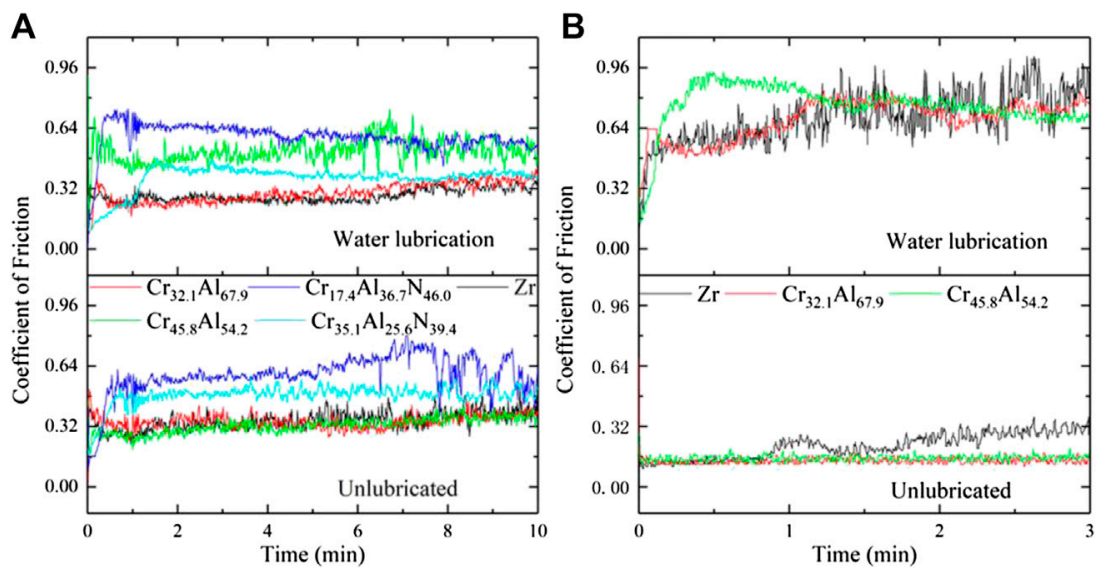

FIGURE 5 | Coefficient of friction of various ATF candidates and Zr-4 under different load: (A) $5 \mathrm{~N}$, (B) $1 \mathrm{~N}$. 


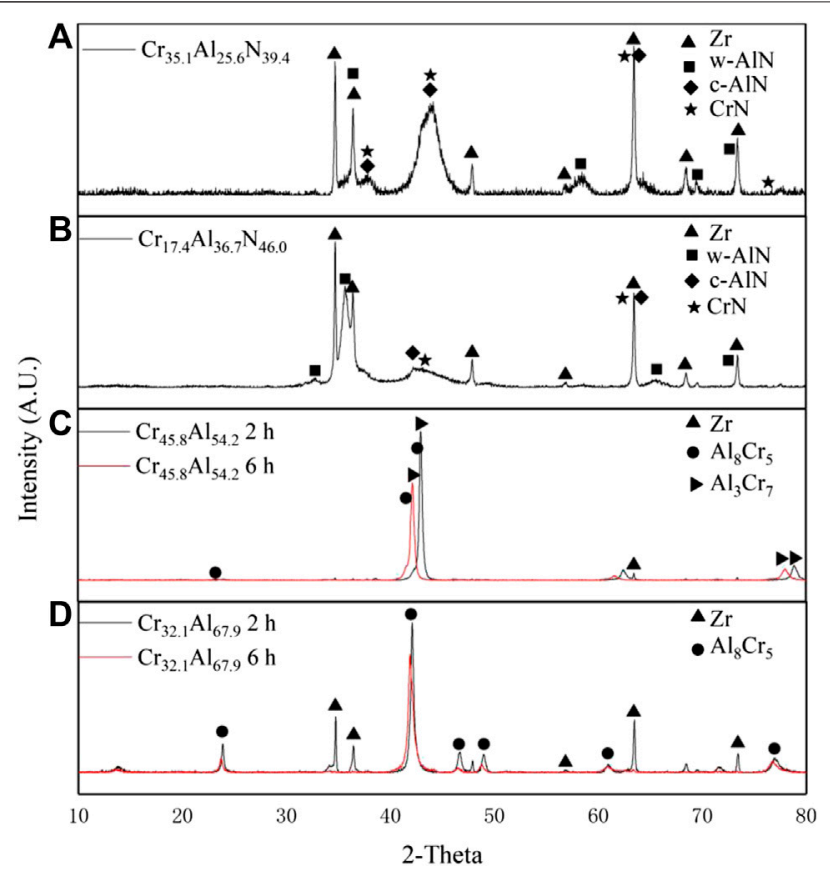

FIGURE 6 | XRD patterns of (A) $\mathrm{Cr}_{35.1} \mathrm{Al}_{25.6} \mathrm{~N}_{39.4}$, (B) $\mathrm{Cr}_{17.4} \mathrm{Al}_{36.7} \mathrm{~N}_{46.0}$, (C) $\mathrm{Cr}_{45.8} \mathrm{Al}_{54.2}$, and (D) $\mathrm{Cr}_{32.1} \mathrm{Al}_{67.9}$ coatings.

\section{Coefficient of Friction}

Figure 5 shows the friction coefficient for different ATF candidates and $\mathrm{Zr}-4$ under water lubrication and unlubricated condition with different loads. The friction coefficient curve showed fluctuations under water lubrication and unlubricated conditions, which lasted until the end of tests. It can be rationalized that under unlubricated condition, since there are worn debris detached from the contact surface and remains on the surface, the worn surface becomes rougher, and then small worn debris may gather in an appropriate position on the irregular worn surface, which may form a worn debris layer.
Therefore, the irregularity and fluctuation of the friction coefficient curve are closely related to the fracture of the worn debris layer and the interaction between the worn debris and the contact surface. It is possible that the frictional debris layer is difficult to be formed under the condition of a small load due to water lubrication. As a result, the fluctuation of the friction coefficient curve is caused by the damage of a surface coating and the periodic accumulation and damage of debris layer on the coating surface.

Under a load of $1 \mathrm{~N}$ without water lubrication, the friction coefficient of $\mathrm{Cr}_{32.1} \mathrm{Al}_{67.9}$ and $\mathrm{Cr}_{45.8} \mathrm{Al}_{54.2}$ is always around 0.15 , indicating that the surface of the $\mathrm{CrAl}$-coating was not severely damaged during the experiment, which is consistent with the previous results of wear depth and wear volume as shown in Figures 2, 3, respectively. Under water lubrication, the friction coefficient is quite different from that under the condition without water lubrication. It can be observed that when other conditions are the same, the coefficient of friction under water lubrication is more significant than that in air condition, which may be related to the viscosity of water. The fluctuation of the friction coefficient curve also reflects a certain change for the coating surface.

Under a load of $5 \mathrm{~N}$, it is noticed that the friction coefficient curves of $\mathrm{CrAl}$ coating and CrAlN coating are distinct. This is due to the fact that the CrAl coating is a metallic coating and the CrAlN coating is a ceramic coating and their surface properties are different. Meanwhile, the coefficient of friction does not increase significantly under water conditions compared to $1 \mathrm{~N}$ with the same condition.

\section{X-Ray Diffraction Analysis}

XRD patterns of $\mathrm{Cr}_{32.1} \mathrm{Al}_{67.9}$ and $\mathrm{Cr}_{45.8} \mathrm{Al}_{54.2}$ coatings with different deposition time and $\mathrm{Cr}_{17.4} \mathrm{Al}_{36.7} \mathrm{~N}_{46.0}, \mathrm{Cr}_{35.1} \mathrm{Al}_{25.6} \mathrm{~N}_{39.4}$ coatings with $2 \mathrm{~h}$ deposition are presented in Figure 6. According to Figures $\mathbf{6 A}, \mathbf{B}$, the c-AlN, w-AlN and $\mathrm{CrN}$ pattern can be detected in the results of $\mathrm{Cr}_{35.1} \mathrm{Al}_{25.6} \mathrm{~N}_{39.4}$ and $\mathrm{Cr}_{17.4} \mathrm{Al}_{36.7} \mathrm{~N}_{46.0}$ coating. The $\mathrm{Cr}_{35.1} \mathrm{Al}_{25.6} \mathrm{~N}_{39.4}$ and $\mathrm{Cr}_{17.4} \mathrm{Al}_{36.7} \mathrm{~N}_{46.0}$ coating have the same composition, nevertheless, their peak distributions are
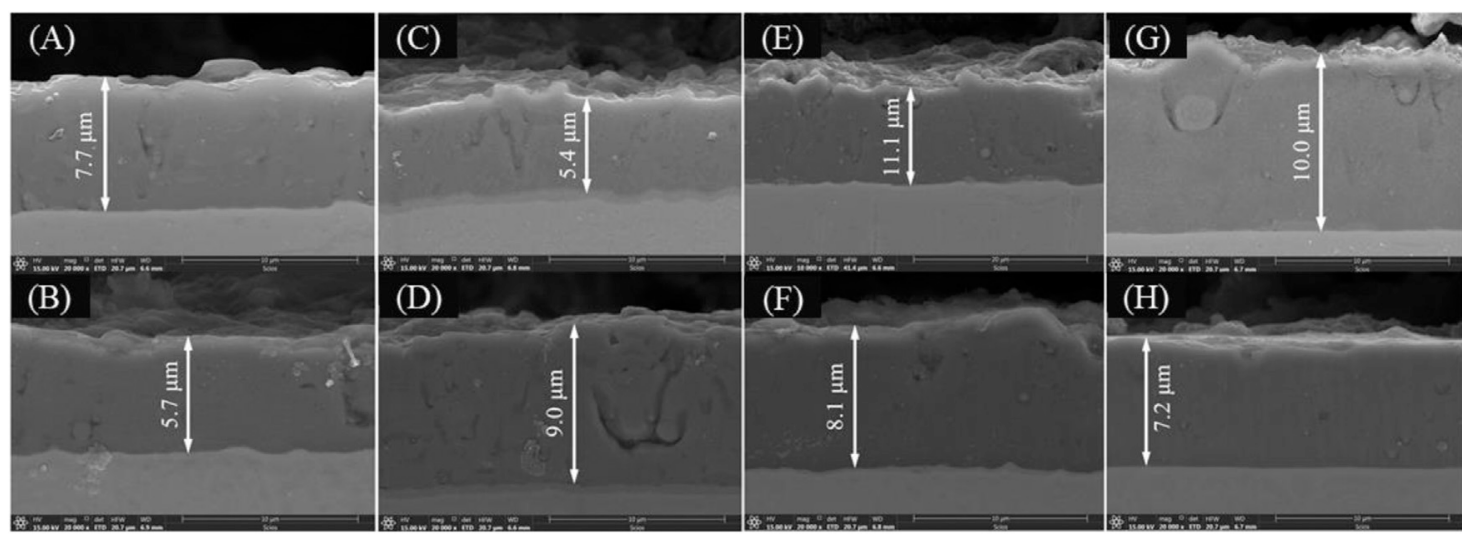

FIGURE 7 | Cross-sectional SEM images of each ATF candidate cladding (deposition time: 2 h), (A) upper side and (B) lower side of Cr 32.1 Al f7.9, $_{\text {, (C) }}$ upper side and (D) lower side of $\mathrm{Cr}_{45.8} \mathrm{Al}_{54.2}$, (E) upper side and (F) lower side of $\mathrm{Cr}_{32.1} \mathrm{Al}_{67.9} \mathrm{~N}$, (G) upper side and $(\mathbf{H})$ lower side of $\mathrm{Cr}_{45.8} \mathrm{Al}_{54.2} \mathrm{~N}$. 
TABLE 2 || Thickness of various ATF coatings with $2 \mathrm{~h}$ deposition.

\begin{tabular}{lccc} 
Materials & $\begin{array}{c}\text { Thickness of } \\
\text { the } \\
\text { upper side }(\mu \mathrm{m})\end{array}$ & $\begin{array}{c}\text { Thickness of } \\
\text { the } \\
\text { lower side }(\mu \mathrm{m})\end{array}$ & $\begin{array}{c}\text { Average thickness } \\
\text { of } \\
\text { two sides }(\mu \mathrm{m})\end{array}$ \\
\hline $\mathrm{Cr}_{32.1} \mathrm{Al}_{67.9}$ & 7.7 & 5.7 & 6.7 \\
$\mathrm{Cr}_{45.8} \mathrm{Al}_{54.2}$ & 5.4 & 9.0 & 7.2 \\
$\mathrm{Cr}_{17.4} \mathrm{Al}_{36.7} \mathrm{~N}_{46.0}$ & 11.1 & 8.1 & 9.6 \\
$\mathrm{Cr}_{35.1} \mathrm{Al}_{25.6} \mathrm{~N}_{39.4}$ & 10.0 & 7.2 & 8.6 \\
\hline
\end{tabular}

quite different. Strong $\mathrm{Al}_{8} \mathrm{Cr}_{5}$ peaks can be observed on both $\mathrm{Cr}_{32.1} \mathrm{Al}_{67.9}$ and $\mathrm{Cr}_{45.8} \mathrm{Al}_{54.2}$ coatings, meanwhile $\mathrm{Al}_{3} \mathrm{Cr}_{7}$ peak is only observed on $\mathrm{Cr}_{45.8} \mathrm{Al}_{54.2}$ coating. Compared with the results of $\mathrm{Cr}_{32.1} \mathrm{Al}_{67.9}$ and $\mathrm{Cr}_{45.8} \mathrm{Al}_{54.2}$ with $2 \mathrm{~h}$ deposition, the XRD results indicate that $\mathrm{CrAl}$ coatings with $6 \mathrm{~h}$ deposition have the same composition, however, the coatings with $6 \mathrm{~h}$ deposition have weaker peak of $\mathrm{Zr}$. The XRD results above indicate that $\mathrm{Cr}, \mathrm{Al}$ and $\mathrm{N}$ elements are well involved in the crystal structure in the coatings, and the crystal structure will change with the change of element type and content. In addition, with the extension of deposition time, the diffraction signal of $\mathrm{CrAl}$ coating also increases, which is the result of the increase of coating thickness.

\section{Scanning Electron Microscopy and Energy-Dispersive X-Ray Spectroscopy Analyses}

Figure 7 shows the results of SEM for four ATF candidate coatings. The measured thickness of each ATF candidate coating is shown in the Table 2 according to the results in Figure 7. The thickness of each coating does not exceed $10 \mu \mathrm{m}$, the hardness of the $\mathrm{CrAl}$ coating is larger than that of $\mathrm{Zr}-4$, meanwhile, the wear depth of CrAl coatings with $2 \mathrm{~h}$ deposition time is pretty close to that of $\mathrm{Zr}-4$, which is due to the coating is relatively thin. When the coating is destroyed, its protective effect on the substrate disappears. The thickness of $\mathrm{Cr}_{32.1} \mathrm{Al}_{67.9}$ and $\mathrm{Cr}_{45.8} \mathrm{Al}_{54.2}$ coating with $2 \mathrm{~h}$ deposition time are thinner than that of $\mathrm{Cr}_{17.4} \mathrm{Al}_{36.7} \mathrm{~N}_{46.0} \mathrm{Cr}_{35.1} \mathrm{Al}_{25.6} \mathrm{~N}_{39.4}$. It can be rationalized by the material compatibility of different coatings, which means the presence of nitrogen accelerates the deposition rate of particles, resulting in a better adhesion for CrAlN with $\mathrm{Zr}-4$. Figure 8 exhibits the SEM result of CrAl coatings with $6 \mathrm{~h}$ deposition. Table 3 reveals the thickness of $\mathrm{CrAl}$ coatings with $6 \mathrm{~h}$ deposition time. As the deposition time increases, the coating remains highly dense, the thickness of the coating increases, and the wear depth does not exceed the thickness of the coating. This also explains the protective effect of the $\mathrm{CrAl}$ coating on the $\mathrm{Zr}$ substrate, that is, it can significantly enhance the wear resistance before the coating is severely damaged.

The distribution of various elements on the coating with $2 \mathrm{~h}$ deposition is shown in the EDS results in Figure 9. The coating and the $\mathrm{Zr}-4$ substrate have a distinct boundary. The substrate does not contain $\mathrm{Cr}, \mathrm{Al}$, and $\mathrm{N}$ elements, and the coating does not contain $\mathrm{Zr}$ elements, which means that the coating does not affect the properties of the $\mathrm{Zr}$ substrate, this also proves that it is feasible to prevent GTRF by physical vapor deposition. When compare the result of Figures 9A-D, it can be seen that the content of $\mathrm{Cr}$ and $\mathrm{Al}$ in the coating is significantly less in the CrAlN coatings. This is consistent with the conclusion that the presence of

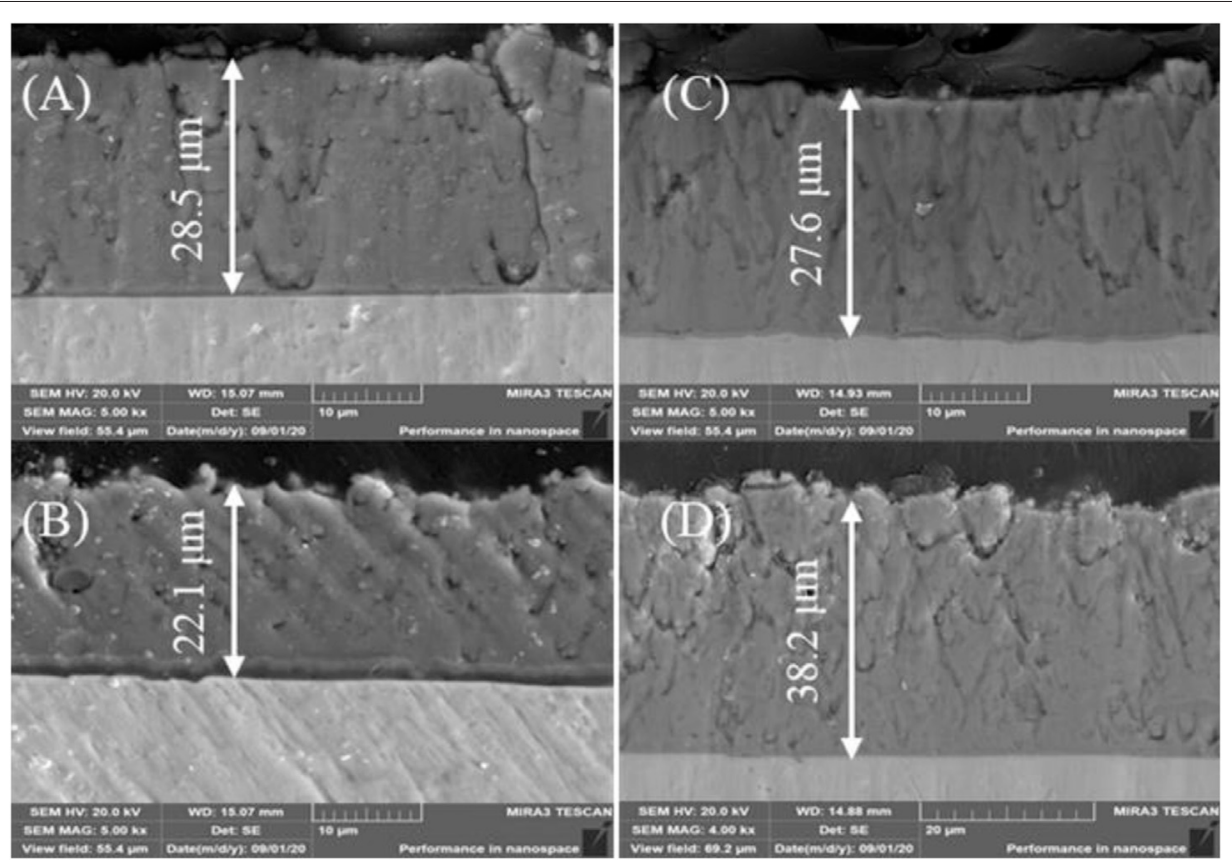

FIGURE 8 | Cross-sectional SEM images of each ATF candidate cladding (deposition time: 6 h), (A) upper side and (B) lower side of Cr 32.1 Al 67.9 , (C) upper side and (D) lower sides of $\mathrm{Cr}_{45.8} \mathrm{Al}_{54.2}$. 
TABLE 3 | Thickness of various ATF coatings with $6 \mathrm{~h}$ deposition.

\begin{tabular}{lccc} 
Materials & $\begin{array}{c}\text { Thickness of the } \\
\text { upper side }(\boldsymbol{\mu m})\end{array}$ & $\begin{array}{c}\text { Thickness of the } \\
\text { lower side }(\boldsymbol{\mu m})\end{array}$ & $\begin{array}{c}\text { Average thickness of } \\
\text { two sides }(\boldsymbol{\mu m})\end{array}$ \\
\hline $\mathrm{Cr}_{32.1} \mathrm{Al}_{67.9}$ & 28.5 & 22.1 & 25.3 \\
$\mathrm{Cr}_{45.8} \mathrm{Al}_{54.2}$ & 27.6 & 38.2 & 32.9
\end{tabular}

nitrogen changes the properties of the coating. Figure 10 reveals the distribution of elements on $\mathrm{CrAl}$ coatings with $6 \mathrm{~h}$ deposition. The distribution of coating elements did not change, indicating that the coating structure would not be affected by the deposition time.

\section{Young's Modulus}

The results of nanoindentation test are presented in Figure 11. Young's modulus of $\mathrm{CrAl}$ coatings are close to that of $\mathrm{Zr}-4$, while the Young's modulus for CrAlN coatings are much higher than that of $\mathrm{Zr}-4$. Considering the Young's modulus and hardness of the samples, the indentation depth of 3,000 $\mathrm{nm}$ and $2000 \mathrm{~nm}$ for $\mathrm{CrAl}$ and CrAlN coatings was chosen, respectively. The Young's modulus of $\mathrm{Cr}_{35.1} \mathrm{Al}_{25.6} \mathrm{~N}_{39.4}$ coating is the highest, followed by $\mathrm{Cr}_{17.4} \mathrm{Al}_{36.7} \mathrm{~N}_{46.0}$ coating. The larger Young's modulus means the smaller elastic deformation under the same stress, which is also consistent with the results of previous friction and wear tests. The larger the Young's modulus is, the substrate will have more efficient protection. However, if the difference of Young's modulus between coating and substrate is huge (e.g., $\mathrm{Cr}_{35.1} \mathrm{Al}_{25.6} \mathrm{~N}_{39.4}$ and $\mathrm{Cr}_{17.4} \mathrm{Al}_{36.7} \mathrm{~N}_{46.0}$ coatings), a superior adhesion between coating and $\mathrm{Zr}-4$ is required. The results of SEM and friction experiment show that the CrAlN coatings have an excellent adhesion, hence, they have a significant protective effect. Meanwhile, for CrAl and CrAlN coatings, the Young's modulus of the coating with high content is larger. This is consistent with the results of hardness and wear behavior of coatings.

\section{SUMMARY AND CONCLUSION}

Various types of accident-tolerant fuel coatings are examined to improve the resistance to grid-to-rod
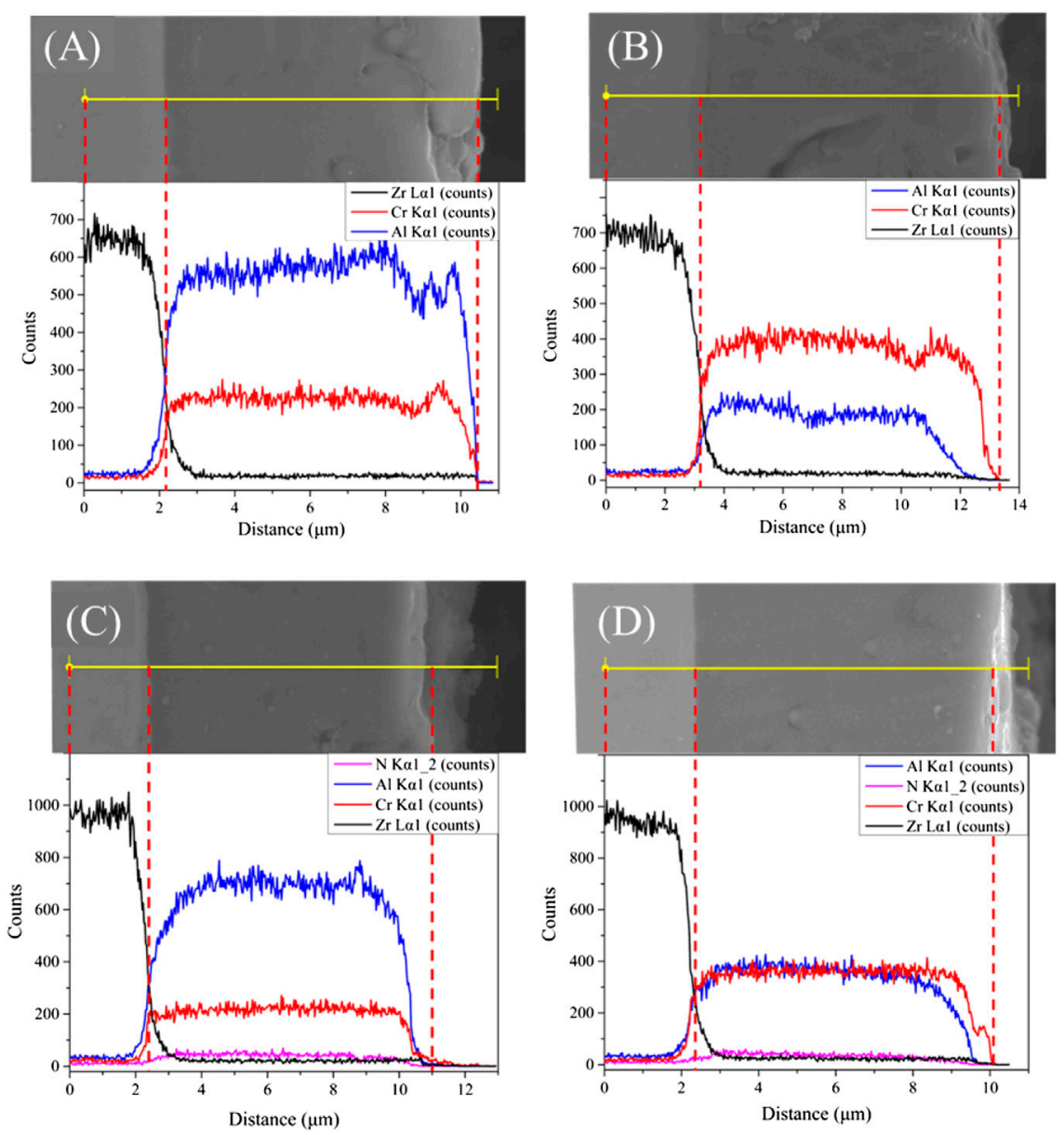

FIGURE 9 | EDS results of cross-section of each ATF candidate cladding with $2 \mathrm{~h}$ deposition: (A) $\mathrm{Cr}_{32.1} \mathrm{Al}_{67.9}$, (B) $\mathrm{Cr}_{45.8} \mathrm{Al}_{54.2}$, (C) $\mathrm{Cr}_{32.1} \mathrm{Al}_{67.9} \mathrm{~N}$, and (D) $\mathrm{Cr}_{45.8} \mathrm{Al}_{54.2} \mathrm{~N}$. 


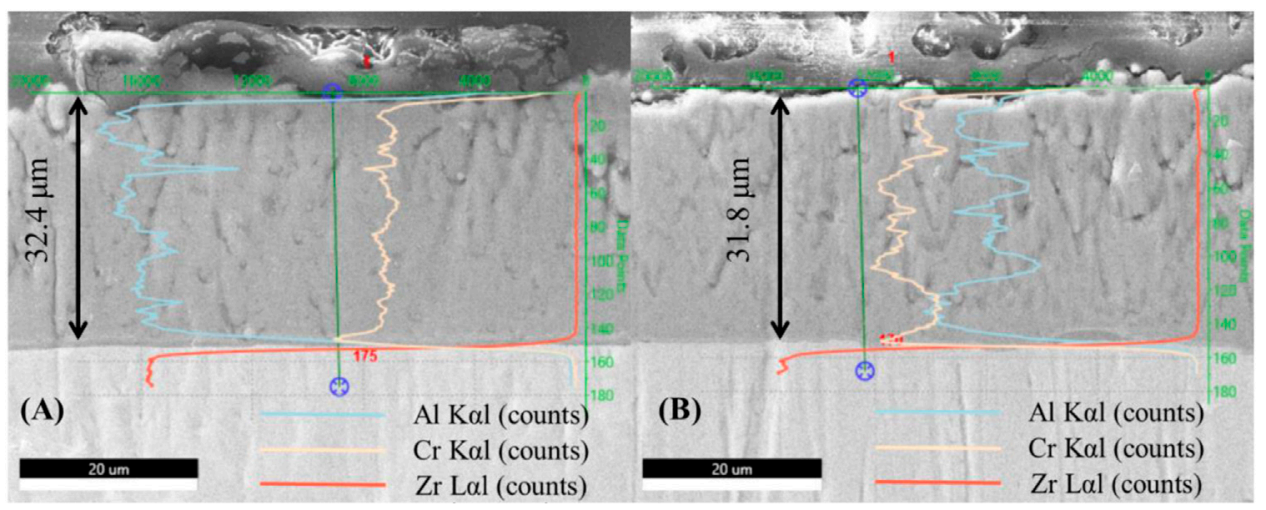

FIGURE 10 | EDS results of cross-section of each ATF candidate cladding with $6 \mathrm{~h}$ deposition: (A) $\mathrm{Cr}_{32.1} \mathrm{Al}_{67.9},(\mathbf{B}) \mathrm{Cr}_{45.8} \mathrm{Al}_{54.2}$

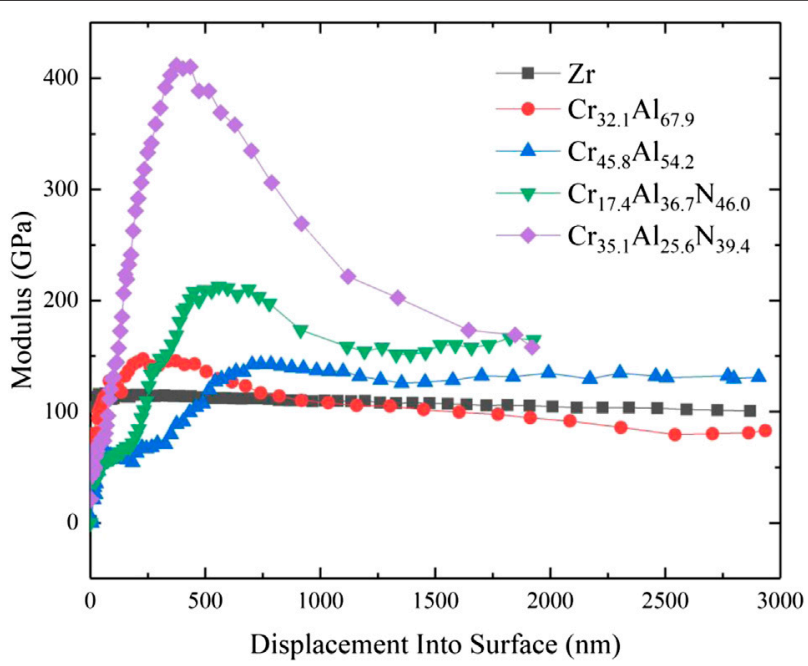

FIGURE 11 | Relationship of Young's modulus-indentation depth for $\mathrm{Zr}$-4 and coatings.

fretting degradation. It was found that CrAl-baesd coatings have a pretty protect effect to $\mathrm{Zr}-4$ substrate, which improve the resistance to GTRF degradation. Furthermore, CrAlN coatings have a better protective effect than CrAl coatings. When the coating is severely damaged, this protective effect of $\mathrm{CrAl}$ coatings will disappear. Under water lubrication, the $\mathrm{CrAl}$ coatings' resistance decrease, whereas the CrAlN coatings' resistance improve. The presence of nitrogen significantly affects coating properties, including coating hardness, abrasion resistance, and coating deposition rate.

Therefore, in order to improve the resistance to grid-to-rod fretting degradation, it is suggested to use coatings with higher hardness (e.g., CrAlN coatings) to deposit on current Zr-4, and the coating should be deposited thicker. Deposit coatings on $\mathrm{Zr}-4$ is a feasible method to improve the resistance to GTRF degradation.

\section{DATA AVAILABILITY STATEMENT}

The raw data supporting the conclusions of this article will be made available by the authors, without undue reservation.

\section{AUTHOR CONTRIBUTIONS}

BM: Original draft preparation BL: Friction and wear experiment and characterization ZW: Article polishing CM: Coating preparation XH: Guide the whole research idea.

\section{FUNDING}

This work was supported by the Fundamental Research Funds for the Central Universities (19lgpy299). 


\section{REFERENCES}

Blandford, E. D., and Ahn, J. (2012). Examining the nuclear accident at Fukushima Daiichi. Elements 8 (3), 189-194. doi:10.2113/gselements.8.3.189

Brachet, J.-C., Le Saux, M., Lezaud-Chaillioux, V., Dumerval, M., Houmaire, Q., Lomello, F., et al. (2016). "Behavior under LOCA conditions of enhanced accident tolerant chromium coated Zircaloy-4 claddings," in Proceedings of the Conference Topfuel 2016, Boise, ID, September 2016 [abstract].

Buesseler, K., Aoyama, M., and Fukasawa, M. (2011). Impacts of the Fukushima nuclear power plants on marine radioactivity. Environ. Sci. Technol. 45 (23), 9931-9935. doi:10.1021/es202816c

Buesseler, K. O., Jayne, S. R., Fisher, N. S., RypinaII, Baumann, H., Baumann, Z., et al. (2012). Fukushima-derived radionuclides in the ocean and biota off Japan. Proc. Natl. Acad. Sci. U.S.A. 109 (16), 5984-5988. doi:10.1073/ pnas.1120794109

Cekić, B., Ćirić, K., Iordoc, M., Marković, S., Mitrić, M., and Stojić, D. (2013). Kinetics of hydrogen absorption in Zr-based alloys. J. Alloys Compd. 559, 162-166. doi:10.1016/j.jallcom.2013.01.104

Chen, L., Xu, Y. X., and Zhang, L. J. (2016). Influence of TiN and ZrN insertion layers on the microstructure, mechanical and thermal properties of $\mathrm{Cr}-\mathrm{Al}-\mathrm{N}$ coatings. Surf. Coating. Technol. 285, 146-152. doi:10.1016/j.surfcoat.2015.11.033

Choudhuri, G., Neogy, S., Sen, D., Mazumder, S., Srivastava, D., Dey, G. K., et al. (2012). Precipitation and growth study of intermetallics and their effect on oxidation behavior in Zr-Sn-Fe-Cr alloy. J. Nucl. Mater. 430 (1-3), 205-215. doi:10.1016/j.jnucmat.2012.07.006

Deck, C. P., Jacobsen, G. M., Sheeder, J., Gutierrez, O., Zhang, J., Stone, J., et al. (2015). Characterization of $\mathrm{SiC}-\mathrm{SiC}$ composites for accident tolerant fuel cladding. J. Nucl. Mater. 466, 667-681. doi:10.1016/j.jnucmat.2015.08.020

Edsinger, K., Deshon, J., Kucuk, A., Mader, E., Cheng, B., Yagnik, S., et al. (2009). "Recent US fuel reliability experience," in Proceedings of the water reactor fuel performance meeting-WRFPM/top fuel, Paris, France, September 6-10, 2009, 268.

He, X., Tian, Z., Shi, B., Xu, X., Meng, C., Dang, W., et al. (2019). Effect of gas pressure and bias potential on oxidation resistance of Cr coatings. Ann. Nucl. Energy. 132, 243-248. doi:10.1016/j.anucene.2019.04.038

He, X., Yang, S., Huang, L., Meng, C., Wang, Y., and Tan, J. (2020). Friction and wear properties of CrSi-based coatings for nuclear fuel cladding. Surf. Coating. Technol. 402, 126311. doi:10.1016/j.surfcoat.2020.126311

Jiang, H., Qu, J., Lu, R. Y., and Wang, J.-A. J. (2016). Grid-to-rod flow-induced impact study for PWR fuel in reactor. Prog. Nucl. Energy. 91, 355-361. doi:10. 1016/j.pnucene.2016.06.003

Katoh, Y., Snead, L. L., Henager, C. H., Nozawa, T., Hinoki, T., Iveković, A., et al. (2014). Current status and recent research achievements in $\mathrm{SiC} / \mathrm{SiC}$ composites. J. Nucl. Mater. 455 (1), 387-397. doi:10.1016/j.jnucmat.2014.06.003

Kim, H.-G., Yang, J.-H., Kim, W.-J., and Koo, Y.-H. (2016). Development status of accident-tolerant fuel for light water reactors in Korea. Nuclear Engineering and Technology. 48 (1), 1-15. doi:10.1016/j.net.2015.11.011

Kim, H.-K., and Lee, Y.-H. (2003). Influence of contact shape and supporting condition on tube fretting wear. Wear 255 (7), 1183-1197. doi:10.1016/S00431648(03)00068-1

Kovács, S., Stabel, J., Ren, M., and Ladouceur, B. (2009). Comparative study on rod fretting behavior of different spacer spring geometries. Wear 266 (1), 194-199. doi:10.1016/j.wear.2008.06.010

Kovács, S., Stabel, J., Ren, M., and Ladouceur, B. (2013). Influence of grid-to-rod fit on fuel rod fretting. Period. Polytech.-Mech. Eng. 57 (1), 7012. doi:10.3311/ PPme.7012

Kuprin, A. S., Belous, V. A., Voyevodin, V. N., Bryk, V. V., Vasilenko, R. L., Ovcharenko, V. D., et al. (2015). Vacuum-arc chromium-based coatings for protection of zirconium alloys from the high-temperature oxidation in air. J. Nucl. Mater. 465, 400-406. doi:10.1016/j.jnucmat.2015.06.016

Kurata, M., Barrachin, M., Haste, T., and Steinbrueck, M. (2018). Phenomenology of BWR fuel assembly degradation. J. Nucl. Mater. 500, 119-140. doi:10.1016/j. jnucmat.2017.12.004
Li, W. Z., Chen, Q. Z., Polcar, T., Serra, R, and Cavaleiro, A. (2014). Influence of Zr alloying on the mechanical properties, thermal stability and oxidation resistance of Cr-Al-N coatings. Appl. Surf. Sci. 317, 269-277. doi:10.1016/j. apsusc.2014.08.115

Ma, X.-F., Wu, Y.-W., Tan, J., Meng, C.-Y., Yang, L., Dang, W.-A., et al. (2019). Evaluation of corrosion and oxidation behaviors of TiAlCrN coatings for nuclear fuel cladding. Surf. Coating. Technol. 358, 521-530. doi:10.1016/j. surfcoat.2018.11.083

Massey, C. P., Terrani, K. A., Dryepondt, S. N., and Pint, B. A. (2016). Cladding burst behavior of Fe-based alloys under LOCA. J. Nucl. Mater. 470, 128-138. doi:10.1016/j.jnucmat.2015.12.018

Meng, C., Yang, L., Wu, Y., Tan, J., Dang, W., He, X., et al. (2019). Study of the oxidation behavior of $\mathrm{CrN}$ coating on $\mathrm{Zr}$ alloy in air. J. Nucl. Mater. 515, 354-369. doi:10.1016/j.jnucmat.2019.01.006

Neu, R. W. (2011). Progress in standardization of fretting fatigue terminology and testing. Tribol. Int. 44 (11), 1371-1377. doi:10.1016/j.triboint.2010. 12.001

Park, J.-H., Kim, H.-G., Park, J.-y., Jung, Y.-I., Park, D.-J., and Koo, Y.-H. (2015). High temperature steam-oxidation behavior of arc ion plated $\mathrm{Cr}$ coatings for accident tolerant fuel claddings. Surf. Coating. Technol. 280, 256-259. doi:10. 1016/j.surfcoat.2015.09.022

Pint, B. A., Terrani, K. A., Yamamoto, Y., and Snead, L. L. (2015). Material selection for accident tolerant fuel cladding. Metall. Mater. Trans. 2 (3), 190-196. doi:10. 1007/s40553-015-0056-7

Rubiolo, P. R. (2006). Probabilistic prediction of fretting-wear damage of nuclear fuel rods. Nucl. Eng. Des. 236 (14), 1628-1640. doi:10.1016/j.nucengdes.2006. 04.023

Rubiolo, P. R., and Young, M. Y. (2009). On the factors affecting the fretting-wear risk of PWR fuel assemblies. Nucl. Eng. Des. 239 (1), 68-79. doi:10.1016/j. nucengdes.2008.08.021

Stone, J. G., Schleicher, R., Deck, C. P., Jacobsen, G. M., Khalifa, H. E., and Back, C. A. (2015). Stress analysis and probabilistic assessment of multi-layer SiC-based accident tolerant nuclear fuel cladding. J. Nucl. Mater. 466, 682-697. doi:10. 1016/j.jnucmat.2015.08.001

Tang, C., Stueber, M., Seifert, H. J., and Steinbrueck, M. (2017). Protective coatings on zirconium-based alloys as accident-tolerant fuel (ATF) claddings. Corrosion Rev. 35 (3), 10. doi:10.1515/corrrev-2017-0010

Terrani, K. A. (2018). Accident tolerant fuel cladding development: promise, status, and challenges. J. Nucl. Mater. 501, 13-30. doi:10.1016/j.jnucmat.2017.12.043

Waterhouse, R. B. (1992). Fretting fatigue. Int. Mater. Rev. 37 (1), 77-98. doi:10. 1179/imr.1992.37.1.77

Zhang, C., Lv, P., Xia, H., Yang, Z., Konovalov, S., Chen, X., et al. (2019). The microstructure and properties of nanostructured $\mathrm{Cr}-\mathrm{Al}$ alloying layer fabricated by high-current pulsed electron beam. Vacuum 167, 263-270. doi:10.1016/j. vacuum.2019.06.022

Zhong, W., Mouche, P. A., and Heuser, B. J. (2018). Response of Cr and Cr-Al coatings on Zircaloy-2 to high temperature steam. J. Nucl. Mater. 498, 137-148. doi:10.1016/j.jnucmat.2017.10.021

Zinkle, S. J., Terrani, K. A., Gehin, J. C., Ott, L. J., and Snead, L. L. (2014). Accident tolerant fuels for LWRs: a perspective. J. Nucl. Mater. 448 (1), 374-379. doi:10. 1016/j.jnucmat.2013.12.005

Conflict of Interest: The authors declare that the research was conducted in the absence of any commercial or financial relationships that could be construed as a potential conflict of interest.

Copyright (C) $2021 \mathrm{Ma}$, Luo, Wang, Meng and He. This is an open-access article distributed under the terms of the Creative Commons Attribution License (CC BY). The use, distribution or reproduction in other forums is permitted, provided the original author(s) and the copyright owner(s) are credited and that the original publication in this journal is cited, in accordance with accepted academic practice. No use, distribution or reproduction is permitted which does not comply with these terms. 